\title{
Sacral Hiatus - A Morphometric and Anatomical Study
}

\author{
Article by Jyothinath Kothapalli \\ Assistant Professor, Department of Anatomy, Maheshwara Medical College \& Hospital, \\ Telangana \\ E-mail: kjyothinath@gmail.com
}

\begin{abstract}
To accurate performance of epidural anaesthesia and analgesia it is important to know the variations of sacral hiatus in dry bone. The present observational study conducted on one hundred dry human sacra to evaluate the anatomical and morphometric variations of sacral hiatus. The most common shape of sacral hiatus was inverted ' $U$ ' and ' $V$ ' respectively. Apex of sacral hiatus present at $3^{\text {rd }}$ sacral segment in $78 \%$ sacra and base is at fifth sacral segment in $89 \%$ sacra. The length of sacral hiatus is between 11-20 mm in majority sacra, anteroposterior diameter is 4-6 mm in 63\% sacra and transverse diameter is 11-15 mm in of sacral hiatus. Anatomical variations in sacral hiatus can leads to caudal epidural anaesthesia failure and procedure related complications. Understanding these variations may improve success of caudal epidural anaesthesia and decrease incidence of complications.
\end{abstract}

Keywords: Sacral hiatus, caudal epidural anaesthesia, Morphometry.

\section{Introduction}

The sacral hiatus is formed by incomplete fusion of the posterior elements of fourth or fifth sacral vertebra [1,2]. Sacral hiatus is very important landmark to conduct caudal epidural anaesthesia or analgesia in patient with low back pain, in obstetrics as well in orthopedic surgeries [3]. There are considerable variations in the size and shape of sacral hiatus which cause difficulty in localization of hiatus during caudal epidural anaesthesia [4]. The present study conducted to explore the anatomical and morphometric variations in the sacral hiatus.

\section{Materials and methods}

This study was conducted in the department of Anatomy, Maheshwara Medical College and Hospital, isnapur, Hyderabad. A total one hundred dry human sacra were considered. Sacra with complete sacral hiatus were included, damaged, deformed, mutilated and exhibiting variations were excluded from the study. The following parameters i.e. shape, level, length, anteroposterior depth, and transverse width of sacral hiatus were measured by using Vernier calipers, steel measuring tape.

\section{Results}

Table 1. Indicating shape of sacral hiatus.

\begin{tabular}{|l|l|l|l|}
\hline SI.NO & Shape & Number & Percentage (\%) \\
\hline 1 & Inverted - U & 58 & 58 \\
\hline 2 & Inverted - V & 19 & 19 \\
\hline 3 & Bifid & 3 & 3 \\
\hline 4 & Absence & 1 & 1 \\
\hline 5 & Spina bifida & 3 & 3 \\
\hline 6 & Irregular & 14 & 14 \\
\hline 7 & Dumbbell & 2 & 2 \\
\hline Total & 100 & 100 \\
\hline
\end{tabular}


Texila International Journal of Basic Medical Science

Volume 2, Issue 1, Jul 2017

\section{POSITION OF SACRAL HIATUS}

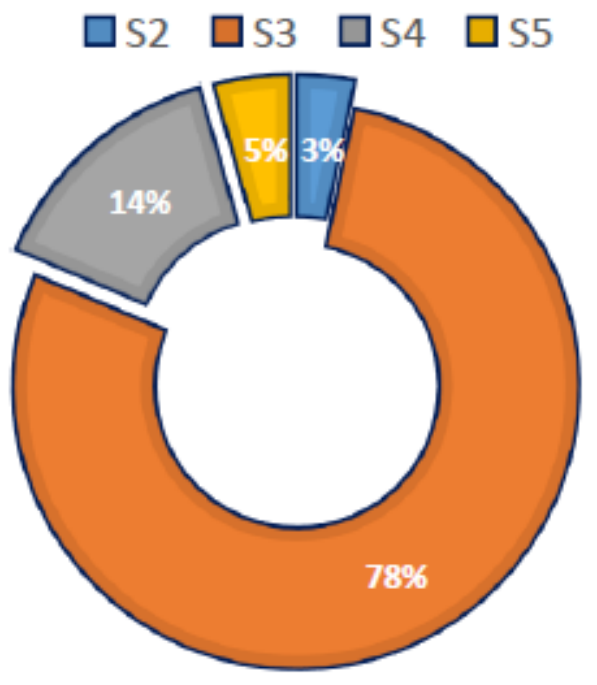

Figure 1. Position of apex of sacral hiatus at various vertebral level.

\section{POSITION OF BASE OF SACRAL HIATUS}

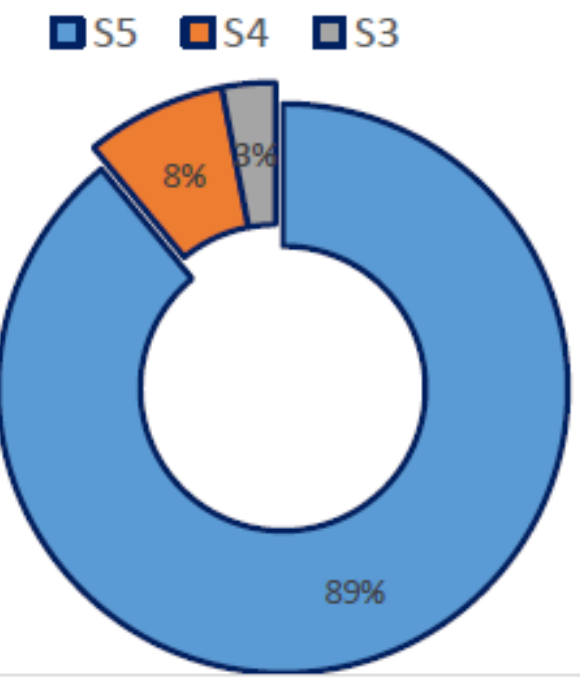

Figure 2. Position of base of sacral hiatus at various vertebral level.

Table 2. Length of sacral hiatus.

\begin{tabular}{|l|l|l|l|}
\hline SI.NO & $\begin{array}{l}\text { Length of sacral hiatus } \\
(\mathrm{mm})\end{array}$ & Number & Percentage (\%) \\
\hline 1 & $0-10$ & 8 & 8 \\
\hline 2 & $11-20$ & 47 & 47 \\
\hline 3 & $21-30$ & 30 & 30 \\
\hline 4 & $31-40$ & 12 & 12 \\
\hline 5 & $41-50$ & 3 & 3 \\
\hline 6 & $>51$ & 0 & 0 \\
\hline
\end{tabular}


Table 3. Transverse diameter of sacral hiatus.

\begin{tabular}{|l|l|l|l|}
\hline SI.NO & Transverse $(\mathrm{mm})$ & Number & Percentage $(\%)$ \\
\hline 1 & $0-5$ & 4 & 4 \\
\hline 2 & $6-10$ & 31 & 31 \\
\hline 3 & $11-15$ & 51 & 51 \\
\hline 4 & $>16$ & 14 & 14 \\
\hline
\end{tabular}

Table 4. Anteroposterior diameter of sacral hiatus.

\begin{tabular}{|l|l|l|l|}
\hline SI.NO & Anteroposterior $(\mathrm{mm})$ & Number & Percentage (\%) \\
\hline 1 & $0-3$ & 30 & 30 \\
\hline 2 & $4-6$ & 63 & 63 \\
\hline 3 & $7-9$ & 7 & 7 \\
\hline 4 & $>9$ & 0 & 0 \\
\hline
\end{tabular}

\section{Discussion}

In the present study, most commonly inverted U shaped (59\%) and inverted V shaped (19\%), sacral hiatus were observed in sacra and considered as normal. Dumb-bell shaped (2\%) which was very low when compared to study by Nagar SK (13.3\%) (20) and Vinod Kumar et al $(7.43 \%)(5,6)$. Bifid sacral hiatus was seen in 3\% sacra which was higher than the findings of Nagar SK. (1.5\%). Kumar et al. (1992) (7) noted various shapes of sacral hiatus in India: Inverted V, inverted U, dumbbell, irregular, bifid, absent, and other shapes and reported that the inverted V shape was the most common shape.

Susan Strandring et al states that the apex of sacral hiatus is present at the level of 4th sacral vertebra [8]. In the present study the apex of sacral hiatus was seen most commonly at the level of third sacral vertebra in $78 \%$ sacra, which was almost similar to Vinod Kumar et al in $76.23 \%$ sacra, but was higher in study conducted by Sekiguchi M et al in $65 \%$. An American based study revealed that the apex of sacral hiatus was posited at the level of S3 in AP lumbosacral spine radiographs [9].

The base of the sacral hiatus in the present study was found at the level of fifth sacral vertebra in $89 \%$. The anteroposterior diameter of sacral hiatus at the apex is important as it should be sufficiently wide to admit a needle. Various diameters lead to subcutaneous or outside deposition of anesthetic drug. The values of AP diameter of sacral hiatus in the present study ranged between 4-6 mm in majority sacra which is similar to the studies by Trotter et al $5.3 \mathrm{~mm}$ (range of $0-11 \mathrm{~mm}$ ), Lanier et al $6.1 \mathrm{~mm}$, Trotter et al $5 \mathrm{~mm}$ in whites and $6 \mathrm{~mm}$ in negro groups, Vinod Kumar et al $4.8 \mathrm{~mm}$ (range of 0- 12 $\mathrm{mm}$ ).Nagar SK. $4.8 \mathrm{~mm}$ (range of 2 - 14mm) and Seikuguchi M et al $6.0 \mathrm{~mm}[10,11]$.

In the present study, the transverse diameter of Sacral Hiatus range was 11-15 mm in majority sacra which is correlating with findings of various workers i.e. Sekiguchi M. et al 10.2 (2.2- 18.4) $\mathrm{mm}$ and Trotter et al- $17 \mathrm{~mm}$ (range of 7- $26 \mathrm{~mm}$ ).

\section{Conclusion}

Sacral hiatus shows morphometric variations various populations. Understanding of these variations may improve the success of caudal epidural anesthesia. Identification of single bony landmark may not be helpful in locating SH. These anatomical variations may be a factor in caudal epidural anaesthesia failure. We should pay attention to anatomical variations of sacral hiatus while performing caudal epidural anaesthesia. When the anesthetist notices an abnormality of the sacral hiatus, he should choose lumbar epidural anaesthesia or other treatments to avoid the risk of the soft tissue injury and the toxicity of local anaesthetics.

\section{References}

[1]. Kumar V, Pandey SN, Bajpai RN, Jain PN, Longia GS. Morphometric study of sacral hiatus. J Anat Soc India. 1992; 41:7-13.

[2]. Lanier VS, Mcknight HE, Trotter M. Caudal analgesia: An experimental and anatomical study. American journal of Obstetrics and Gynaecology 1944; 47(5): 633 - 641.

[3]. Letterman GS, Trotter M. Variations of the male sacrum: Their significance in caudal analgesia. Surg Gynecol Obstet. 1944; 78:551-5. 
Texila International Journal of Basic Medical Science

Volume 2, Issue 1, Jul 2017

[4]. Manisha B. Sinha, Mrithunjay Rathore, Human Prasad Sinha: A Study of variation of sacral hiatus in dry bone in central Indian region; International J. of Healthcare and Biomedical Research, Volume: 2, Issue: 4, July 2014, Pages 46-52.

[5]. Nagar SK. A study of sacral hiatus in dry human sacra. Journal of Anatomical Society of India 2004; 53(2): $18-21$.

[6]. Standring S, Newell RLM, Collins P, Healy JC. In the back in; Gray's Anatomy, The anatomical basis of clinical practice. 40th Edition. ISBN; 978-0-8089-2371-8. SPAIN, CHURCHILL Livingstone Elsevier, 2008; pp; 724-5 2.

[7]. Standring S, Ellis H, Healy JC, Johnson D. Gray's anatomy. 39th ed. Vol. 1431. London: Elsevier Churchill Livingstone; 2005. pp. 749-54.

[8]. Sekiguchi M., Yabuki S., Satoh K., Kikuchi S. (2004) an anatomic study of the sacral hiatus: a basis for successful caudal epidural block. Clin. J. Pain 20: 51-54.

[9]. Trotter M, Letterman GS, Gordon S, Variations of the female Sacrum: their significance in continuous caudal anesthesia. Surg., Gynec. And Obst. 1944; 78:419-424.

[10]. Vinod kumar et al. Morphometrical study of sacral hiatus. Journal of Anatomical society of India 1992; 41(1): $7-13$.

[11]. Waldman SD caudal epidural nerve block; prone position in - Atlas of interventional Pain Management, 2nd edn. Philadelphia; Saunder 2004; 380-92. 